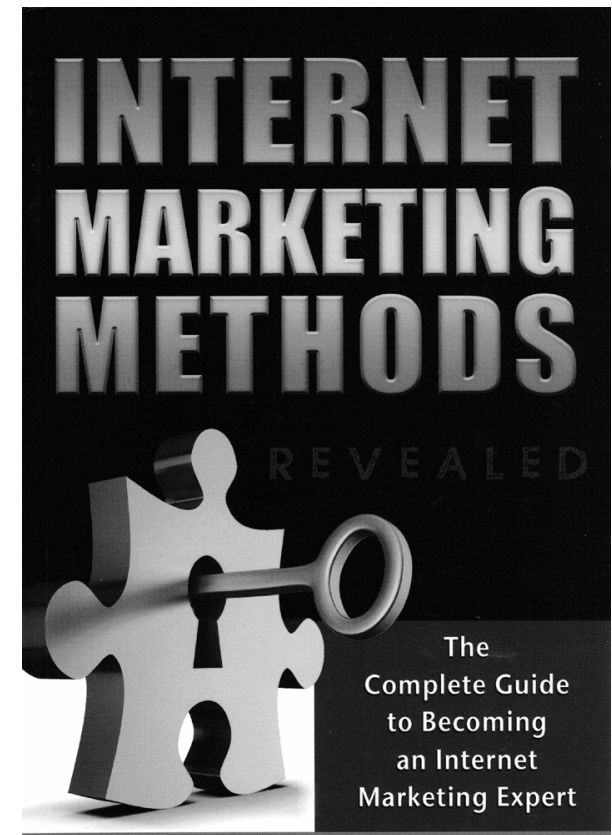

BY MIGUEL TODARO

\section{Marketing por Internet}

\author{
Por María Inés Rocca
}

¿Cómo lograr que una organización aparezca mejor rankeada en los portales de búsqueda en Internet? ¿Qué criterio utilizan los grandes motores de búsqueda, como Google o Yahoo, para ubicar a una organización en los primeros lugares de búsqueda relacionadas al posicionamiento en Internet? Éstas y otras preguntas que varios nos hemos hecho en torno a este tema son las que Miguel Todaro pretende contestar en su libro Internet Marketing Methods Revealed.

En este libro usted podrá entender la diferencia entre lo que es una pauta online paga -como son los enlaces patrocinados o las campañas Pay Per Click- y los llamados rankings orgánicos, es decir los resultados en los motores de búsqueda. El autor deja entrever que no existen recetas mágicas, sino que se deben conocer todas las alternativas y elegir la más beneficiosa para los objetivos y públicos de la organización.

Así como se ha hecho popular en los últimos años la palabra "googlear", hoy se habla de hacer "SEO"
(Search Engine Optimization), refiriéndose a la optimización de los sitios web y de los vínculos con otros sitios, para figurar mejor rankeados en los buscadores. Antes se creía que existía cierta correlación entre la cantidad de ingresos a un sitio web y su posicionamiento en los rankings de búsqueda, pero hoy eso ya es un mito. La fórmula para figurar entre los mejores lugares del ranking sólo las grandes compañías como Google o Yahoo la saben. Estos rankings surgen del resultado de varias asociaciones y fórmulas matemáticas que varios han querido revelar y que Todaro, de una manera clara y sencilla, comparte con el lector. Así también nos enseña las técnicas más efectivas para diseñar avisos y la importancia de su nomenclatura para el éxito de las campañas online.

Este libro es una alternativa para todas aquellas personas que deseen iniciarse en el camino del posicionamiento en Internet. Tal como dice su nombre, revela secretos y formas de optimizar la presencia de la marca online.::
Título::

Internet Marketing Methods Revealed: The Complete Guide to Becoming an Internet Marketing Expert.

Autor::

Miguel Todaro.

Editorial:: Atlantic Publishing

Group, inc., USA.

Año::

2007 